\title{
Hydroxychloroquine/chloroquine in patients with COVID-19 in Wuhan, China: a retrospective cohort study
}

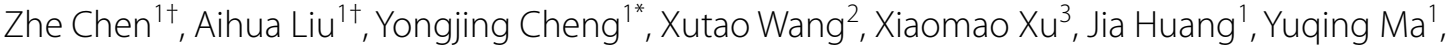 \\ Ming Gao and Cibo Huang ${ }^{1}$
}

\begin{abstract}
Background: Since the COVID-19 pandemic, several therapeutic agents have been used in COVID-19 management. However, the results were controversial. Here, we aimed to evaluate the efficacy and safety of hydroxychloroquine (HCQ)/chloroquine (CQ) in COVID-19.

Methods: We retrospectively reviewed the medical charts of patients with COVID-19 admitted to an inpatient ward in Wuhan from 2020/Feb/08 to 2020/Mar/05. Patients with HCQ/CQ and age, gender, disease severity matched ones without $\mathrm{HCQ} / \mathrm{CQ}$ were selected at a 1:2 ratio. The clinical, laboratory and imaging findings were compared between these two groups. The multivariate linear regression analysis was performed to identify the factors that might influence patients' virus shedding periods (VSPs).

Results: A total of 14 patients with $\mathrm{HCQ} / \mathrm{CQ}$ and 21 matched ones were analyzed. The HCQ/CQ treatment lasted for an average of $10.36 \pm 3.12$ days. The mean VSPs were longer in the HCQ/CQ treatment group (26.57 \pm 10.35 days vs. $19.10 \pm 7.80$ days, $P=0.020$ ). There were 3 patients deceased during inpatient period, two patients were with $\mathrm{HCQ} / \mathrm{CQ}$ treatment $(P=0.551)$. In the multivariate linear regression analysis, disease durations at admission $(t=3.643, P=0.001)$ and $\mathrm{HCQ} / \mathrm{CQ}$ treatment $(\mathrm{t}=2.637, P=0.013)$ were independent parameters for patients ${ }^{\prime} \mathrm{VSP}$. One patient with CQ had recurrent first-degree atrioventricular block (AVB) and obvious QTc elongation, another one complained about dizziness and blurred vision which disappeared after CQ discontinuation. One patient with HCQ had transient AVB.

Conclusions: In summary, we identify that the HCQ/CQ administration is not related to less mortality cases at later phase of COVID-19. More studies are needed to explore whether HCQ/CQ treatment would lead to SARS-Cov-2 RNA clearance delay or not.
\end{abstract}

Keywords: Hydroxychloroquine, Chloroquine, Virus shedding periods, COVID-19

\section{Background}

Since December 2019, the outbreak of severe acute respiratory syndrome coronavirus 2 (SARS-Cov-2) infection has swept over the whole world in a few months. By May

\footnotetext{
*Correspondence: chengyongjing3427@bjhmoh.cn

†Z Zhe Chen and Aihua Liu contributed equally to this article

${ }^{1}$ Department of Rheumatology, Beijing Hospital, National Center

of Gerontology, Beijing, China

Full list of author information is available at the end of the article
}

5, 2020, more than 3.5 million cases have been confirmed and the death toll raises to over 250 thousand all around the world. The SARS-Cov-2 infection results in the coronavirus disease-2019 (COVID-19), which is composed of a spectrum of clinical manifestations including pneumonia, heart/kidney/liver injury, and coagulopathy, etc. [1, 2].

Due to lacking of specific anti-virus drugs, the management of COVID-19 is still challenging. The results of two randomized controlled clinical trials of the promising 
anti-virus agents, i.e. Lopinavir/Ritonavir and Remdesivir, showed that these drugs were not that effective as we had expected in Chinese patients with COVID-19 [3, 4]. Because of the dramatic elevation of several inflammatory factors, such as interferon- $\gamma$-induced protein 10 , monocyte chemotactic protein-3, interleukin-13, et al., overreactive immunopathological mechanisms were surmised to be responsible for multiple organ damage in COVID-19 [5]. Some researchers hypothesized that patients with COVID-19 might benefit from some antirheumatic drugs, such as hydroxychloroquine (HCQ)/ chloroquine (CQ) and tocilizumab (TCZ), for their dual effects on immune regulation and suppression [6].

$\mathrm{CQ}$ is a traditional anti-malaria drug. As a derivate of CQ, HCQ is less toxic to retina and heart and is the background treatment in systemic lupus erythematosus (SLE) [7]. Yu and colleagues reported that HCQ treatment could reduce serum interleukin-6 (IL-6) levels in COVID-19 patients [8]. Except for the anti-inflammatory activity, HCQ/CQ has potential anti-virus effects $[9,10]$. Liu et al. reported that both HCQ and CQ could inhibit SARS-Cov-2 replication and prevent the virus from entering into cells in vitro [11]. HCQ/CQ was recommended as an option in the COVID-19 management guideline in China [12, 13]. Furthermore, both the US Food and Drug Administration and the Indian Council for Medical Research had permitted the empiric use of HCQ in COVID-19 patients [14, 15]. With the surging demands for HCQ in COVID-19, some patients under long-term HCQ treatment for autoimmune disease, such as SLE, were threatened by HCQ shortage. Therefore, some rheumatologists campaigned for using $\mathrm{HCQ}$ rationally in COVID-19 in which the data and evidence were limited and inconclusive [16]. Unfortunately, the efficacy of HCQ/CQ in COVID-19 remained equivocal by far.

At the very beginning of the outbreak of COVID-19, a multidisciplinary medical team from Beijing Hospital took in charge of an independent inpatient ward to manage the COVID-19 patients in the Sino-French New City Branch of Tongji Hospital in Wuhan, China. Some patients took $\mathrm{HCQ} / \mathrm{CQ}$ during their inpatient period. We performed the following retrospective analysis to evaluate the potential efficacy and safety of $\mathrm{HCQ} / \mathrm{CQ}$ in COVID-19.

\section{Methods}

\section{Patients}

Medical charts of patients admitted to one inpatient ward in Wuhan from February 08, 2020 to March 05, 2020 were reviewed. Due to the potential while uncertain efficacy of TCZ in COVID-19, patients receiving TCZ treatment were excluded from the study. Patients with HCQ/
CQ treatment and age, gender, disease severity matched ones without $\mathrm{HCQ} / \mathrm{CQ}$ treatment were analyzed. The matching process was performed with the SPSS software (version 26.0) and the propensity-score (PS) matching package at a 1:2 ratio. The Caliper value was 0.2 .

\section{Methods}

This was a retrospective cohort study. The demographic data, clinical manifestations, comorbidities, laboratory findings and image involvement patterns assessed by computed tomography $(\mathrm{CT})$ were carefully and thoroughly collected from medical charts.

The disease severity was defined as mild, general, severe and critically severe according to the Chinese management guideline for COVID-19 (Additional file 1) [12]. The CURB-65 severity score was calculated according to the standard definition [17]. The estimated glomerular filtration rate (eGFR) was calculated via the CKD-EPI equation [18]. The concurrent respiratory pathogen infections, including type A influenza, type B influenza, mycoplasma pneumoniae, chlamydia pneumoniae, respiratory syncytial virus, adenovirus, parainfluenza virus and legionella pneumophilia infections, were confirmed by the presence of pathogen specific immunoglobulin $M$ with the enzyme-linked immunosorbent assay.

The nasopharyngeal swabs were sampled based on physicians' judgement on clinical purposes. And the ribonucleic acids (RNAs) of SARS-Cov-2 were examined with the polymerase chain reaction (PCR) method [19]. The virus shedding periods (VSPs) were defined from symptoms onset to the first day of the consecutive negative PCR results before discharge (Additional file 1). Drugs taken by the patients for COVID-19 management purposes before admission were recorded and analyzed as well. Receiving corticosteroids (GCs) treatment was defined as exposure to systemic GCs. The dosage of GCs was calculated by methylprednisolone (MP) (prednisone: methylprednisolone $=1.25: 1$ ). The complains and symptoms after $\mathrm{HCQ} / \mathrm{CQ}$ initiation were carefully recorded.

\section{Statistical analysis}

Statistics analyses were conducted with the SPSS software (version 26.0). Numerical data was expressed as mean \pm standard deviation (SD) or quartiles (Q1: first quartile; Q2: second quartile; Q3: third quartile), while categorical data was expressed as numbers and percentages. Numerical data was compared with the independent sample $t$-test. Categorical data was compared with the Chi-square or the Fisher's exact test, as appropriate. The multivariate linear regression analysis was performed to identify the factors that might influence patients' VSPs. Virus shedding periods were the dependent variable. Continuous or dichotomous parameters, such as 
disease duration at admission, with or without HCQ/ CQ treatment, dosage of GCs et al. selected according to clinical judgment, were analyzed as probable predict variables with the stepwise method in the multivariate linear regression analysis (Additional file 1: Table S1). Laboratory results which were statistically different between patients with and without $\mathrm{HCQ} / \mathrm{CQ}$ were selected as probable predict variables as well. MP dosage in patients without GCs was recorded as zero. All probabilities were 2 -sided, and $P$ values $<0.05$ were considered to be statistically significant.

\section{Results}

From February 8, 2020 to March 5, 2020, a total of 63 COVID-19 patients were admitted to our ward. All the patients were confirmed with SARS-Cov-2 infection via PCR. Except for 5 patients who received TCZ treatment, 58 patients were treated by non-biological drugs. Among the 58 patients, 11 and 3 patients received HCQ and CQ treatment, respectively. After age, gender and disease severity matching, 21 patients without $\mathrm{HCQ} /$
CQ treatment were selected as controls and were further analyzed (Fig. 1).

For the 35 patients, the average age was $62.20 \pm 11.88$ years old with a male predominance. The span from symptoms onset to admission were $13.00 \pm 7.24$ days. Although common at disease onset (77.14\%), fever was observed in only $20 \%$ of patients at admission. Twenty-six patients (74.28\%) had at least a comorbidity, most of which was hypertension. Twentyone out of the 35 patients suffered from multiple pathogen infections in addition to SARS-Cov-2. And influenza was the most common concomitant infectious disease (57.14\%) (Table 1). Procalcitonin elevation was recorded in 9 patients. Serum ferritin and IL-6 levels were elevated in 34 and 17 patients, respectively. Serum IL-1 $\beta$, IL-2R, IL-8, IL-10 and tumor necrosis factor- $\alpha$ (TNF- $\alpha$ ) levels were tested in 14 patients. As a result, serum IL-1 $\beta$, IL-2R, IL-8, IL-10 and TNF- $\alpha$ elevation were recorded in $1,8,2,0$ and 6 patients, respectively.

Twenty-two patients took anti-influenza drugs, i.e., oseltamivir or arbidol or both. Most patients (94.28\%) received traditional Chinese medicine (TCM) treatment.

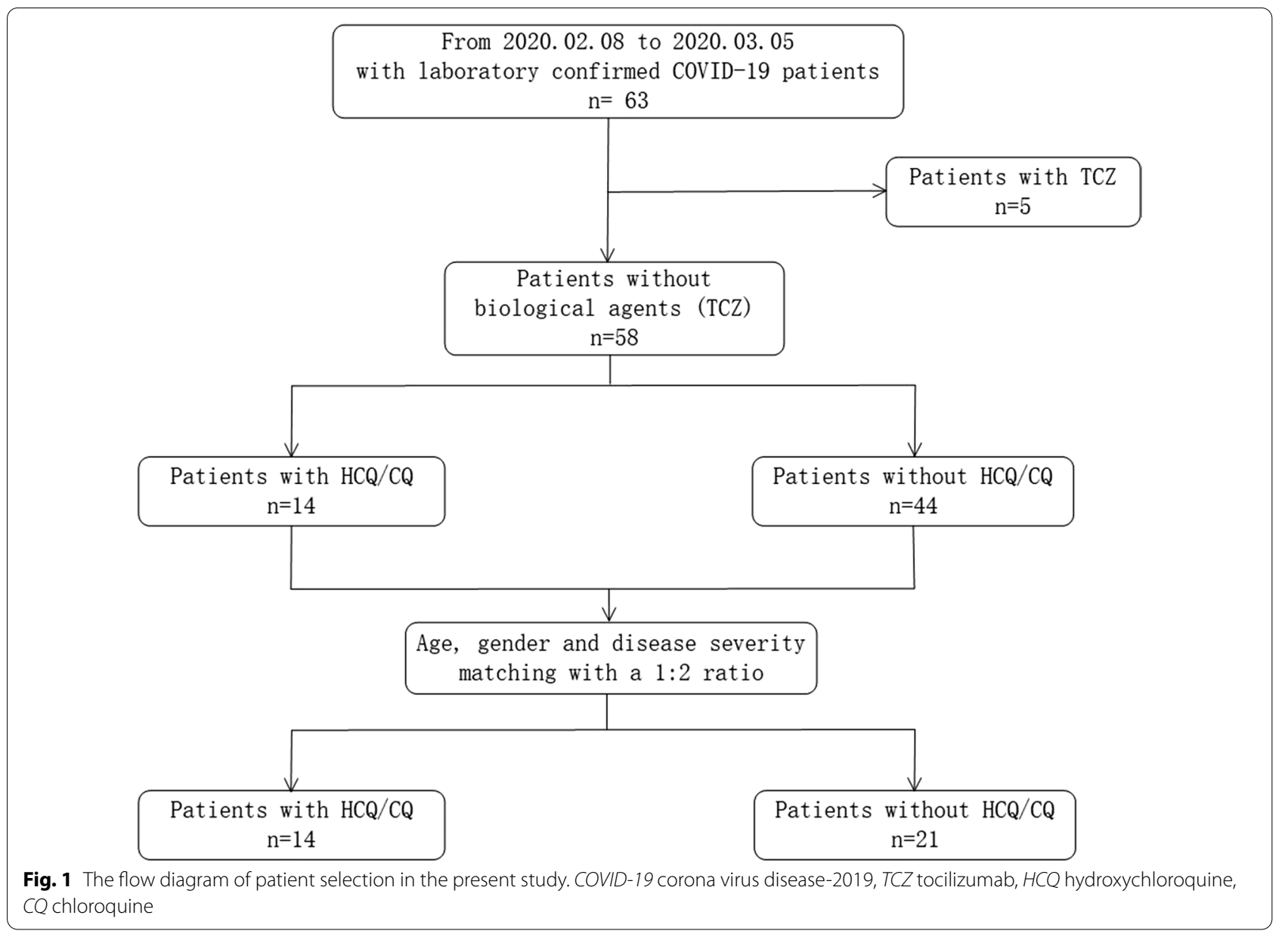


Table 1 Clinical characteristics, laboratory and imaging findings of the 35 patients at admission

\begin{tabular}{|c|c|c|c|c|}
\hline & Total $(n=35)$ & With HCQ/CQ $(n=14)$ & Without HCQ/CQ $(n=21)$ & $P$ value \\
\hline Age & $62.20 \pm 11.88$ & $61.00 \pm 13.00$ & $63.00 \pm 11.33$ & 0.633 \\
\hline Male & 23 & 10 & 13 & 0.721 \\
\hline Disease duration (days) & $13.00 \pm 7.24$ & $13.00 \pm 7.14$ & $13.00 \pm 7.49$ & 1.000 \\
\hline \multicolumn{5}{|c|}{ Clinical manifestation at beginning } \\
\hline Fever & 27 & 10 & 17 & 0.685 \\
\hline Fatigue & 25 & 11 & 14 & 0.704 \\
\hline Cough & 26 & 12 & 14 & 0.262 \\
\hline Diarrhea & 8 & 3 & 5 & 1.000 \\
\hline Myalgia/arthralgia & 10 & 7 & 3 & 0.053 \\
\hline Fever at admission & 7 & 2 & 5 & 0.676 \\
\hline \multicolumn{5}{|l|}{ Comorbidities } \\
\hline Hypertension & 13 & 7 & 6 & 0.199 \\
\hline Diabetes mellites & 5 & 2 & 3 & 1.000 \\
\hline Carcinoma $^{a}$ & 5 & 3 & 2 & 0.369 \\
\hline Stroke & 1 & 1 & 0 & 0.400 \\
\hline Coronary artery disease & 2 & 1 & 1 & 1.000 \\
\hline Lung disease ${ }^{b}$ & 6 & 1 & 5 & 0.366 \\
\hline HBV infection & 7 & 3 & 4 & 1.000 \\
\hline \multicolumn{5}{|l|}{ Disease severity status } \\
\hline General & 19 & 7 & 12 & 0.678 \\
\hline Severe/critical & 16 & 7 & 9 & \\
\hline \multicolumn{5}{|l|}{ CURB-65 score } \\
\hline 0 & 15 & 6 & 9 & 1.000 \\
\hline $1-5$ & 20 & 8 & 12 & \\
\hline \multicolumn{5}{|l|}{ Laboratory results } \\
\hline $\operatorname{WBC}\left(\times 10^{9} / \mathrm{L}\right)$ & $6.13 \pm 2.45$ & $6.27 \pm 2.96$ & $6.05 \pm 2.12$ & 0.801 \\
\hline $\operatorname{Neu}\left(\times 10^{9} / \mathrm{L}\right)$ & $4.33 \pm 2.38$ & $4.68 \pm 2.88$ & $4.10 \pm 2.01$ & 0.490 \\
\hline $\operatorname{Lym}\left(\times 10^{9} / \mathrm{L}\right)$ & $1.08 \pm 0.52$ & $1.05 \pm 0.56$ & $1.09 \pm 0.50$ & 0.828 \\
\hline Neu/Lym & $5.27 \pm 4.31$ & $6.16 \pm 5.13$ & $4.69 \pm 3.67$ & 0.329 \\
\hline $\mathrm{Hb}(\mathrm{g} / \mathrm{L})$ & $123.17 \pm 18.43$ & $126.14 \pm 19.22$ & $121.19 \pm 18.08$ & 0.444 \\
\hline $\operatorname{PLT}\left(\times 10^{9} / \mathrm{L}\right)$ & $266.37 \pm 111.96$ & $283.86 \pm 110.58$ & $254.71 \pm 114.04$ & 0.459 \\
\hline $\operatorname{ALT}(\mathrm{U} / \mathrm{L})$ & $33.14 \pm 28.69$ & $27.00 \pm 21.31$ & $37.24 \pm 32.56$ & 0.308 \\
\hline AST (U/L) & $32.11 \pm 20.96$ & $27.00 \pm 13.72$ & $35.52 \pm 24.37$ & 0.244 \\
\hline Alb (g/L) & $33.26 \pm 5.60$ & $31.94 \pm 6.51$ & $34.14 \pm 4.87$ & 0.260 \\
\hline $\mathrm{LDH}(\mathrm{U} / \mathrm{L})$ & $282.69 \pm 126.59$ & $310.00 \pm 130.40$ & $264.48 \pm 123.78$ & 0.304 \\
\hline $\mathrm{eGFR}\left(\mathrm{mL} / \mathrm{min} / 1.73 \mathrm{~m}^{2}\right)$ & $89.33 \pm 15.88$ & $86.17 \pm 12.15$ & $91.43 \pm 17.92$ & 0.345 \\
\hline$>90 \mathrm{~mL} / \mathrm{min} / 1.73 \mathrm{~m}^{2}$ & 20 & 7 & 13 & 0.486 \\
\hline$\leq 90 \mathrm{~mL} / \mathrm{min} / 1.73 \mathrm{~m}^{2}$ & 15 & 7 & 8 & \\
\hline Fibrinogen ( $\mathrm{g} / \mathrm{L})$ & $5.17 \pm 1.59$ & $5.82 \pm 1.19$ & $4.74 \pm 1.66$ & 0.045 \\
\hline D-Dimer (ug/mL FEU) & $3.63 \pm 5.42$ & $4.30 \pm 6.65$ & $3.18 \pm 4.54$ & 0.556 \\
\hline$>1.0 \mathrm{ug} / \mathrm{mL}$ FEU & 21 & 8 & 13 & 0.778 \\
\hline$\leq 1.0 \mathrm{ug} / \mathrm{mL} \mathrm{FEU}$ & 14 & 6 & 8 & \\
\hline NT-pro-BNP (ug/mL) & $253.20 \pm 346.51$ & $318.29 \pm 520.19$ & $209.81 \pm 152.60$ & 0.372 \\
\hline$c \operatorname{Tnl}(\mathrm{pg} / \mathrm{mL})$ & $9.11 \pm 9.51$ & $8.43 \pm 9.38$ & $9.56 \pm 9.79$ & 0.736 \\
\hline $\operatorname{ESR}(\mathrm{mm} / \mathrm{h})(/ \mathrm{n})$ & $47.75 \pm 26.74(32)$ & $58.62 \pm 19.90(13)$ & $40.32 \pm 28.70(19)$ & 0.056 \\
\hline hsCRP (mg/L) & $33.89 \pm 38.61$ & $31.47 \pm 24.06$ & $35.50 \pm 46.39$ & 0.767 \\
\hline Procalcitonin $(\mathrm{ng} / \mathrm{mL})$ & $0.17 \pm 0.46$ & $0.10 \pm 0.08$ & $0.21 \pm 0.60$ & 0.507 \\
\hline$\geq 0.1 \mathrm{ng} / \mathrm{mL}$ & 9 & 5 & 4 & 0.432 \\
\hline$<0.1 \mathrm{ng} / \mathrm{mL}$ & 26 & 9 & 17 & \\
\hline
\end{tabular}


Table 1 (continued)

\begin{tabular}{|c|c|c|c|c|}
\hline & Total $(n=35)$ & With HCQ/CQ $(n=14)$ & Without $\mathrm{HCQ} / \mathrm{CQ}(\mathrm{n}=21)$ & $P$ value \\
\hline Ferritin (ug/L) (n) & $819.36 \pm 628.02(31)$ & $689.45 \pm 494.53(13)$ & $913.18 \pm 707.92(18)$ & 0.336 \\
\hline IL-6 (ug/mL) (n) & $14.49 \pm 15.62(31)$ & $13.28 \pm 9.27(13)$ & $15.37 \pm 19.19(18)$ & 0.721 \\
\hline $\begin{array}{l}\text { Other respiratory pathogen infection }{ }^{c} \\
\text { Imaging findings }\end{array}$ & 21 & 10 & 11 & 0.260 \\
\hline GGO & 30 & 14 & 16 & 0.069 \\
\hline Consolidation & 19 & 7 & 12 & 0.678 \\
\hline Bilateral pulmonary infiltration & 34 & 14 & 20 & 1.000 \\
\hline Interstitial changes & 17 & 7 & 10 & 0.890 \\
\hline Hydrothorax & 7 & 1 & 6 & 0.203 \\
\hline
\end{tabular}

HBV hepatitis B virus, WBC white blood cell, Neu neutrophil, Lym lymphocyte, $H b$ hemoglobulin, PLT platelet, $A L T$ alanine transaminase, $A S T$ oxaloacetic transaminase, LDH lactate dehydrogenase, eGFR estimated glomerular filter rate, NT-pro-BNP N-terminal pro-Brain Natriuretic Peptide, cTnl cardiac troponin I, ESR erythrocyte sedimentation rate, $h s C R P$ high sensitivity $C$ reactive protein, IL-6 interleukin-6, GGO ground glass opacity, HCQ hydroxychloroquine, CQ chloroquine

${ }^{a}$ Including carcinoma in the stomach $(n=2)$, urinary bladder $(n=1)$, bone $(n=1)$ and breast $(n=1)$

${ }^{b}$ Lung disease refers to chronic obstructive lung disease $(n=3)$, emphysema $(n=2)$, bronchiectasis $(n=1)$, lung fibrosis $(n=1)$ and bullae $(n=1)$

' Other concurrent respiratory pathogen infection with a specific serum immunoglobulin $M$ positive confirmed by the enzyme-linked immunosorbent assay includes type A influenza $(n=18)$, type B influenza $(n=2)$, mycoplasma pneumoniae $(n=2)$ and chlamydia pneumoniae $(n=1)$

And the total types of anti-virus agents were similar between these two treatment groups (Table 2). Antibiotics were concomitantly administrated with $\mathrm{HCQ} / \mathrm{CQ}$ in 17 patients. And moxifloxacin was the most commonly used antibiotic (13/17). HCQ/CQ was not administrated in combination with azithromycin in our patients. GCs were administrated in $12(34.28 \%)$ patients. There were more patients taking GCs in the HCQ/CQ treatment group (57.14\% vs. $19.05 \%, P=0.031$ ) (Table 2 ). The detailed information of GCs was available in 11 patients. Patients took GCs at a median of 14 days after symptoms onset (Q1: 12 days, Q3: 19 days). The GCs treatment lasted for a median of 6 days (Q1: 4 days, Q3: 7 days).

Table 2 Treatment and outcomes of the 35 patients

\begin{tabular}{|c|c|c|c|c|}
\hline & Total $(n=35)$ & With HCQ/CQ $(n=14)$ & Without $\mathrm{HCQ} / \mathrm{CQ}(\mathrm{n}=21)$ & $P$ value \\
\hline \multicolumn{5}{|l|}{ Treatment } \\
\hline \multicolumn{5}{|l|}{ Antivirus agents } \\
\hline Ribavirin & 9 & 4 & 5 & 1.000 \\
\hline Lopinavir/Ritonavir & 4 & 1 & 3 & 0.635 \\
\hline Oseltamivir & 18 & 8 & 10 & 0.581 \\
\hline Arbidol & 10 & 6 & 4 & 0.151 \\
\hline TCM & 33 & 14 & 19 & 0.506 \\
\hline Types of antivirus agents & $2.11 \pm 0.93$ & $2.36 \pm 0.75$ & $1.95 \pm 1.02$ & 0.213 \\
\hline Corticosteroids & 12 & 8 & 4 & 0.031 \\
\hline IVIG & 9 & 4 & 5 & 1.000 \\
\hline Antibiotics & 22 & 10 & 12 & 0.392 \\
\hline Anticoagulant & 8 & 3 & 5 & 1.000 \\
\hline Virus shedding period (days) & $22.09 \pm 9.51$ & $26.57 \pm 10.35$ & $19.10 \pm 7.80$ & 0.020 \\
\hline Swab testing times & $3.81 \pm 2.04$ & $5.15 \pm 2.38$ & $2.89 \pm 1.10$ & 0.001 \\
\hline $\begin{array}{l}\text { Consecutive swab testing negative times } \\
\text { before discharging }\end{array}$ & $3.03 \pm 1.23$ & $3.23 \pm 1.42$ & $2.89 \pm 1.10$ & 0.457 \\
\hline Swab testing interval (days) & $6.10 \pm 1.63$ & $5.77 \pm 1.36$ & $6.34 \pm 1.80$ & 0.346 \\
\hline \multicolumn{5}{|l|}{ Outcomings } \\
\hline Discharged & 32 & 12 & 20 & 0.551 \\
\hline Deceased & 3 & 2 & 1 & \\
\hline
\end{tabular}

TCM traditional Chinese medicine, IVIG intravenous immune globulin, HCQ hydroxychloroquine, CQ chloroquine 
And the median cumulated dosage of GCs was $280 \mathrm{mg}$ (MP or equivalent, Q1: $160 \mathrm{mg}, \mathrm{Q} 3: 480 \mathrm{mg}$ ).

The dosage of HCQ was either $200 \mathrm{mg}(\mathrm{n}=5)$ or $400 \mathrm{mg}(\mathrm{n}=6)$ twice a day. And the dosage of CQ was $500 \mathrm{mg}(\mathrm{n}=3)$ twice a day (Fig. 2). The average disease duration before $\mathrm{HCQ} / \mathrm{CQ}$ initiation was $21.00 \pm 5.98$ days (Q1: 16.50 days; Q2: 22.00 days; Q3: 26.25 days). The HCQ/CQ treatment lasted for an average of $10.36 \pm 3.12$ days (Q1: 10.75 days; Q2: 11.00 days; Q3: 12.00 days). Only 1 of the 14 patients received $\mathrm{HCQ} / \mathrm{CQ}$ treatment after virus shedding. The
SARS-Cov-2 RNA tests turned negative after an average of $7.31 \pm 6.05$ days (Q1: 3.00 days; Q2: 5.00 days; Q3: 9.50 days) since $\mathrm{HCQ} / \mathrm{CQ}$ initiation in the rest 13 patients. The average VSPs were $22.09 \pm 9.51$ days, which was a little longer in the $\mathrm{HCQ} / \mathrm{CQ}$ treatment group (26.57 \pm 10.35 days vs. $19.10 \pm 7.80$ days, $P=0.020$ ). However, the average swab testing intervals didn't differ between patients with and without HCQ/CQ treatment statistically $(5.77 \pm 1.36$ days vs. $6.34 \pm 1.80$ days, $P=0.346$ ) (Table 2). For the patients whose VSPs were longer than 22 days, the

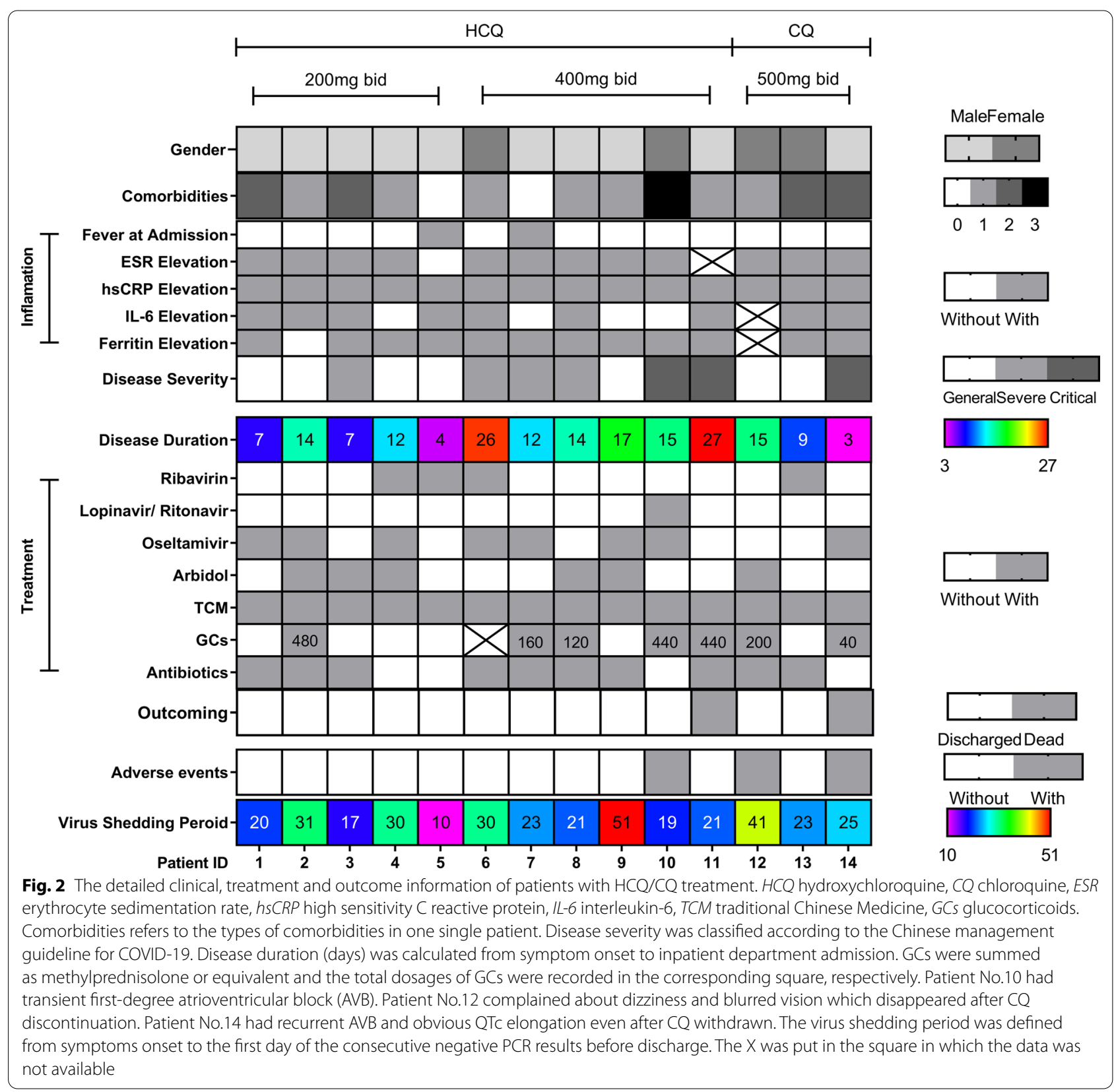


differences of average VSPs in patients with and without $\mathrm{HCQ} / \mathrm{CQ}$ treatment were not statistically different $(31.75 \pm 9.72$ days $/ \mathrm{n}=8$ vs. $28.67 \pm 3.56$ days $/ \mathrm{n}=6$, $P=0.477)$. In the multivariate linear regression analysis, disease durations at admission $(\mathrm{t}=3.643, P=0.001)$ and HCQ/CQ treatment $(\mathrm{t}=2.637, P=0.013)$ were independent predict parameters for patients' VSPs prediction (Additional file 1: Table S1). The linear regression formulation was listed as following. Here is an example. One male patient with COVID-19 was admitted to the hospital at the 5th day after symptom onset. He received HCQ therapy in the hospital. Therefore his expected virus shedding period was $21(10.039+0$ $.697 \times 5+7.140 \times 1=20.664)$ days. Meanwhile, neither GCs treatment $(\mathrm{t}=-0.313, P=0.772)$ nor GCs dosage $(\mathrm{t}=-0.706, P=0.766)$ was related to VSPs statistically. And after treatment, acute exudation lesions were largely absorbed in pulmonary CT (Fig. 3). There were 3 patients deceased during inpatient period in our study, and two patients were with HCQ/CQ treatment $(P=0.551)$. Two patients died from multiple organ failure. And the other patient died suddenly. Their relatives refused of autopsy. Thus, the exact reasons for their death were unknown.

Virus shedding period (days) $=10.039+0.697 \times$ disease durations at admission $+7.140 \times$ with or without $\mathrm{HCQ} /$ CQ treatment $(0$, if without $\mathrm{HCQ} / \mathrm{CQ}$ treatment; 1 , if with $\mathrm{HCQ} / \mathrm{CQ}$ treatment).

Electrocardiographs (ECGs) were conducted at least once in 12 out of the 14 patients ( 9 patients with $\mathrm{HCQ}$ treatment, and 3 patients with CQ treatment). Firstdegree atrioventricular block (AVB) was recorded in 2 patients. One patient received HCQ and the other received CQ. No second or third AVB was noticed. Firstdegree AVB disappeared after HCQ discontinuation. However, the first-degree AVB disappeared after CQ

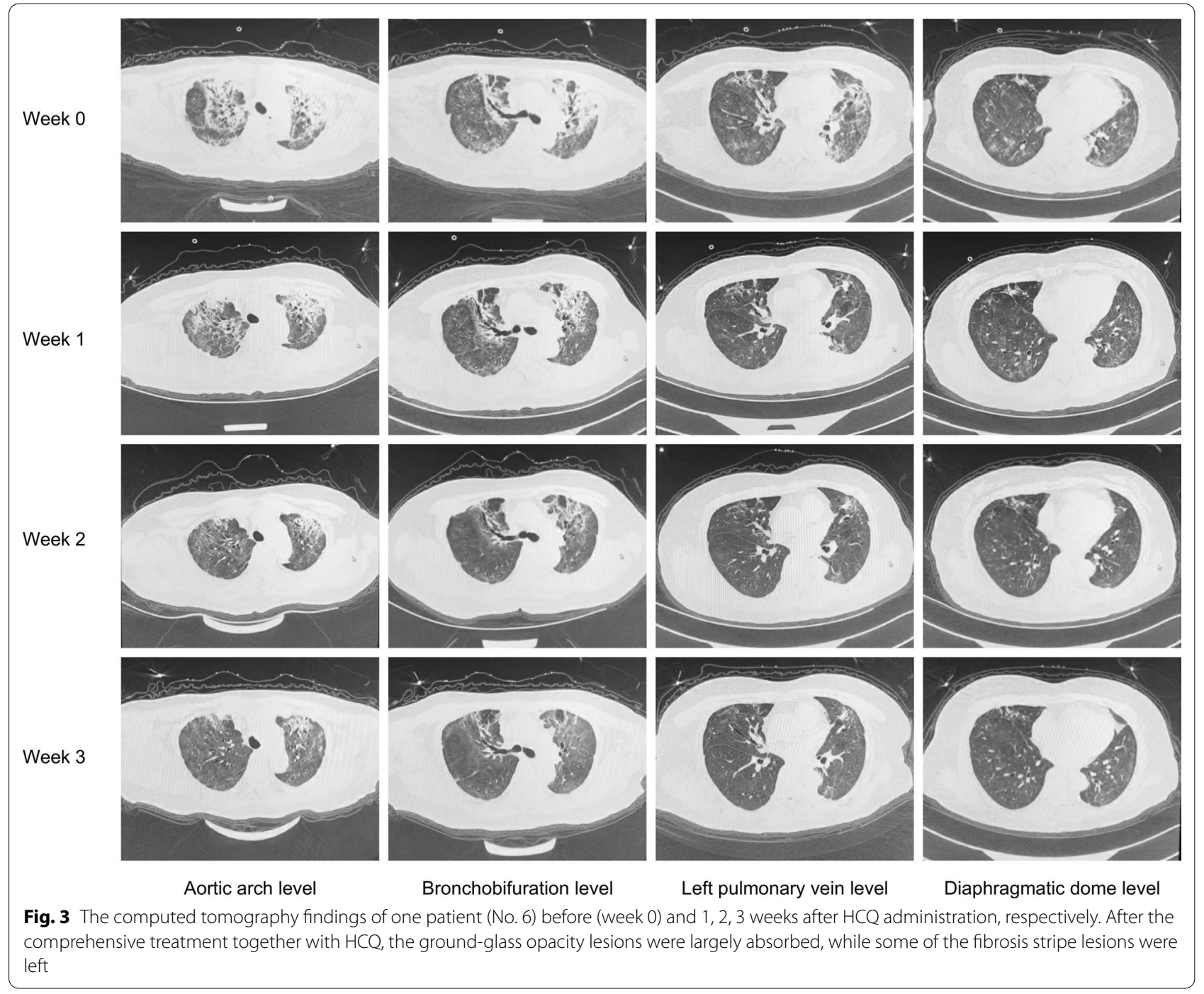


discontinuation and reoccurred 10 days later. The QTc interval longer than $500 \mathrm{~ms}$ was recorded in the identical patient with CQ treatment. Another patient with CQ treatment complained about dizziness and blurred vision. And the symptoms disappeared after CQ being withdrawn. No patient complained about new symptoms during HCQ treatment.

\section{Discussion}

The conventional anti-malaria drug $\mathrm{HCQ} / \mathrm{CQ}$ was regarded as a promising agent for its dual effects on inflammation modulation and virus inhibition since the beginning of the pandemic $[12,14,15]$.

During the past decades, several researchers had confirmed the anti-virus effects of HCQ/CQ in vitro and in vivo $[7,9,10]$. HCQ/CQ could prevent the coronavirus from entering the host cells by interfering with endosomal acidification which is essential for membrane fusion. However, coronavirus could invade the host cells via alternative non-endosomal pathway which is not blocked by HCQ/CQ [20]. CQ could also interfere with virus post translation modification by pondus hydrogenii $(\mathrm{PH})$ modulation [21]. At the meantime, $\mathrm{HCQ} / \mathrm{CQ}$ could act on host cells directly. HCQ/CQ could inhibit glycosylation of the cell membrane protein angiotensin converting enzyme-2, to which the SARS-Cov- 2 is attached [22]. HCQ/CQ could downregulate the toll like receptor (TLR) on activated immune cells and block TLR signal transduction, and prohibit inflammatory factors secretion, such as IL-6 $[8,23]$.

By far, a few clinical studies have analyzed the efficacy of HCQ/CQ in COVID-19. Gautret and colleagues reported that most patients with COVID-19 were virologicaly cured 6 days after HCQ initiation, especially those who received HCQ in combination with azithromycin [24]. However, Gautret et al's study had a relatively small sample size and two selection bias. First, patients in the treatment and control group were not from the same medical center. Second, the virus loads in the HCQ treatment group were lower compared to those in the control group at inclusion. Lower virus loads indicated that the patients in the HCQ treatment group were at a later disease phase of SARS-Cov-2 infection and were more likely to have autolimiting disease course [25]. In a randomized clinical trial (RCT), Chen and colleagues reported that after HCQ treatment with a dosage of $400 \mathrm{mg} /$ day for 5 days, the clinical and radiological improve rates were higher compared to those in patients without HCQ treatment $(80.6 \%$ vs. $54.8 \%)$ [26]. In another randomized study with mildly to moderately ill COVID-19 patients, Tang et al. noticed that the SARS-Cov-2 negative conversion rates were similar in patients with and without HCQ treatment $(85.4 \%$ vs. $81.3 \%)$ [27]. In a retrospective study,
Mallat and colleagues reported that HCQ treatment was an independent factor for longer VSPs. The median time span from nasopharyngeal swab positivity to negativity were 17 days in the HCQ treatment group and 10 days in the control group, respectively $(P=0.023)$. HCQ was administrated at an early stage of the disease course in Mallat's study [28].

In our study, the number of mortality cases were not statistically different between patients with and without $\mathrm{HCQ} / \mathrm{CQ}$ treatment. The result might be ascribed to several factors. Firstly, HCQ/CQ was administrated at a later phase of the disease course. In some patients, we used HCQ/CQ due to persistent SARS-Cov-2 RNA positivity for salvage treatment purposes. It is widely accepted that anti-virus should be taken as early as possible in influenza and corona virus infection $[4,29]$. Secondly, the half-life of $\mathrm{HCQ} / \mathrm{CQ}$ is as long as 40-60 days due to the large distribution volume in the blood. And it usually takes several weeks before $\mathrm{HCQ} / \mathrm{CQ}$ reaching its maximal activity [30]. In COVID-19, HCQ/CQ treatment only lasted for an average of 10 days. Therefore, $\mathrm{HCQ} / \mathrm{CQ}$ might be withdrawn before it worked. Thirdly, for ethic factors concern, several kinds of drugs, such as GCs, ribavirin, TCM et al., were administrated empirically and anecdotally at the same time. These concomitantly taken drugs might have covered up the potential therapeutic effects of HCQ/CQ on COVID-19. Fourthly, due to the small sample size, the death rates were not statistically different in patients with and without HCQ/CQ treatment. Taken together, the efficacy of HCQ/CQ in COVID-19 management should be verified in large randomized controlled trials.

In the present study, the average VSPs were similar to those reported in the previous study [31]. After the multivariate linear regression analysis, we identified that disease durations at admission and HCQ/CQ treatment were independent parameters related to patients' VSPs, indicating patients might have better prognosis if being well treated earlier. Furthermore, VSPs were not statistically different between patients with longer VSPs (VSPs $>22$ days) in these two treatment groups. It was interesting that there were more patients who took GCs in the HCQ/CQ treatment group. However, after being adjusted by other confounders, neither GCs treatment nor GCs dosage was an independent parameter for VSPs prediction. Actually, the effect of GCs on COVID-19 remains controversial and disputable. In SARS and Middle East Respiratory Syndrome (MERS), GCs administration was related to delayed virus RNA clearance [32, 33]. However, in the SARS or MERS studies, patients were either critically ill [33] or took rather high GCs dosage [32]. On the other hand, patients with SARS or influenza might benefit from low-to-moderate GCs $[34,35]$. In the 
present study, our patients took a low-to-moderate dose of GCs during a relative short period of time. As a result, we didn't find correlations between GCs treatment and prolonged VSPs. A team consist of front-line physicians from the Chinese Thoracic Society suggested that after careful benefits and harms evaluation, short term low-tomoderate dose of GCs could be prudently administrated in patients with COVID-19 [36].

One of the major concerns for $\mathrm{HCQ} / \mathrm{CQ}$ treatment in COVID-19 is the side effect [37]. HCQ/CQ related retinopathy always occurs after months even years of HCQ/ CQ administration [30]. Meanwhile, HCQ/CQ related arrythmia might be lethal. And the risk is rising together with other arrhythmogenic drugs, such as azithromycin [30]. Borba et al. reported that high dose of CQ $(600 \mathrm{mg}$ twice daily) was related to prolonged QTc interval and should not be recommended in critically ill patients [38]. Lane and colleagues reported that HCQ monotherapy was safe in COVID-19. However, HCQ in addition to azithromycin might result in heart failure and cardiovascular mortality [39]. Tang et al. found that HCQ was safe in patients with COVID-19, the most common adverse effects were diarrhea and vomiting [27]. Similarly, HCQ was safe and tolerable in our patients. On the contrast, among the three patients with CQ treatment, one patient complained about dizziness and blurred vision and another patient had recurrent first-degree AVB and obvious QTc elongation.

The major limitation of the study was the relatively small sample size. There were only 14 patients received HCQ/CQ treatment due to the unsettled debate on the safety profile of HCQ/CQ in COVID-19. The sample size of the patients without HCQ/CQ was expected to be 28 . However, after age, gender and disease severity matching, only 21 patients without HCQ/CQ treatment met the matching criteria and were finally selected. Secondly, some patients were treated with HCQ/CQ for persistent SARS-Cov-2 RNA positivity. These patients, per se, were refractory to treatment. Therefore, selection bias exists in our patients. Thirdly, due to the retrospective nature of the study, although we found out that HCQ/CQ treatment was related to longer VSPs, we couldn't tell whether $\mathrm{HCQ} / \mathrm{CQ}$ prolonged SARS-Cov-2 RNA clearance or not.

\section{Conclusions}

In summary, we identify that the HCQ/CQ administration is not related to neither less mortality cases nor shorter VSPs at later phase of COVID-19. More studies are needed to explore whether HCQ/CQ treatment would lead to SARS-Cov-2 RNA clearance delay or not. And HCQ other than CQ is a safe and tolerable drug in COVID-19 patients.

\section{Abbreviations}

HCQ: Hydroxychloroquine; CQ: Chloroquine; SARS-Cov-2: Severe acute respiratory syndrome coronavirus 2; COVID-19: Corona virus disease-2019; SLE: Systemic lupus erythematosus; IL-6: Interleukin-6; CT: Computed tomography; eGFR: Estimated glomerular filtration rate; RNAs: Ribonucleic acids; PCR: Polymerase chain reaction; VSPs: Virus shedding periods; GCs: Corticosteroids; MP: Methylprednisolone; SD: Standard deviation; TNF-a: Tumor necrosis factor-a; TCM: Traditional Chinese medicine; ECGs: Electrocardiographs; AVB: Atrioventricular block; TLR: Toll like receptor; RCT: Randomized clinical trial; MERS: Middle East Respiratory Syndrome.

\section{Supplementary Information}

The online version contains supplementary material available at https://doi. org/10.1186/s12879-021-06477-x.

Additional file 1. The disease severity definition and discharging criteria according to the Chinese management guideline for COVID-19. Table S1. The details of model for VSPs prediction.

\section{Acknowledgements}

We thank all the medical workers from Beijing Hospital who treated patients in the Sino-French New City Branch of Tongji Hospital in Wuhan. We thank all the patients and their families involved in the study.

\section{Authors' contributions}

All authors were involved in drafting the article or revising it critically for important intellectual content. $\mathrm{YC}$ and $\mathrm{CH}$ had full access to all of the data in the study and take responsibility for the integrity of the data and the accuracy of the data analysis. $\mathrm{AL}, \mathrm{YC}, \mathrm{XW}, \mathrm{XX}, \mathrm{MG}$ and $\mathrm{CH}$ designed this study initially. $\mathrm{ZC}, \mathrm{JH}$ and $\mathrm{YM}$ were responsible for data acquisition. ZC and AL analyzed and interpreted the data. $\mathrm{ZC}$ and $\mathrm{AL}$ drafted the main manuscript of the article. All authors read and approved the final manuscript.

\section{Funding}

This research did not receive any specific grant from funding agencies in the public, commercial, or not-for-profit sectors.

\section{Availability of data and materials}

The datasets used and/or analyzed during the current study are available from the corresponding author on reasonable request.

\section{Declarations}

\section{Ethics approval and consent to participate}

The study was approved by the institutional review board of Beijing Hospital (Approval letter number: 2020BJYYEC-084-01). Written informed consent has been obtained from all participants.

Consent for publication

Not applicable.

\section{Competing interests}

The authors declare that they have no competing interests to disclose.

\section{Author details}

${ }^{1}$ Department of Rheumatology, Beijing Hospital, National Center of Gerontology, Beijing, China. ${ }^{2}$ Department of Emergency, Beijing Hospital, National Center of Gerontology, Beijing, China. ${ }^{3}$ Department of Pulmonary and Critical Care Medicine, Beijing Hospital, National Center of Gerontology, Beijing, China.

Received: 31 July 2020 Accepted: 27 July 2021

Published online: 12 August 2021 


\section{References}

1. Guan WJ, Ni ZY, Hu Y, et al. Clinical characteristics of coronavirus disease 2019 in China. N Engl J Med. 2020;382(18):1708-20. https://doi org/10.1056/NEJMoa2002032.

2. Zhang $Y$, Xiao M, Zhang S, et al. Coagulopathy and antiphospholipid antibodies in patients with Covid-19. N Engl J Med. 2020;382(17):e38. https://doi.org/10.1056/NEJMc2007575.

3. Cao B, Wang Y, Wen D, et al. A trial of lopinavir-ritonavir in adults hospitalized with severe Covid-19. N Engl J Med. 2020;382(19):1787-99. https://doi.org/10.1056/NEJMoa2001282.

4. Wang YM, Zhang DY, Du GH, et al. Remdesivir in adults with severe COVID-19: a randomised, double-blind, placebo-controlled, multicentre trial. Lancet. 2020;395(10236):1569-78. https://doi.org/10.1016/ s0140-6736(20)31022-9.

5. Yang Y, Shen C, Li J, et al. Plasma IP-10 and MCP-3 levels are highly associated with disease severity and predict the progression of COVID19. J Allergy Clin Immunol. 2020. https://doi.org/10.1016/j.jaci.2020.04. 027.

6. Sanders JM, Monogue ML, Jodlowski TZ, et al. Pharmacologic treatments for coronavirus disease 2019 (COVID-19): a review. JAMA. 2020 https://doi.org/10.1001/jama.2020.6019.

7. Hughes G. Hydroxychloroquine: an update. Lupus. 2018;27(9):1402-3. https://doi.org/10.1177/0961203318787040.

8. Yu B, Li C, Chen P, et al. Low dose of hydroxychloroquine reduces fatality of critically ill patients with COVID-19. Sci China Life Sci. 2020. https://doi.org/10.1007/s11427-020-1732-2

9. Aguirre-Cruz L, Torres KJ, Jung-Cook H, et al. Short communication: preferential concentration of hydroxychloroquine in adenoid tissue of HIV-infected subjects. AIDS Res Hum Retrovir. 2010;26(3):339-42. https://doi.org/10.1089/aid.2009.0129.

10. Ferner RE, Aronson JK. Chloroquine and hydroxychloroquine in covid19. BMJ. 2020;369:m1432. https://doi.org/10.1136/bmj.m1432.

11. Liu J, Cao R, Xu M, et al. Hydroxychloroquine, a less toxic derivative of chloroquine, is effective in inhibiting SARS-CoV-2 infection in vitro. Cell Discov. 2020;6:16. https://doi.org/10.1038/s41421-020-0156-0.

12. National Health Commission of the People's Republic of China. Chinese management guideline for COVID-19 (version 6.0). http://www.nhc. gov.cn/yzygj/s7653p/202002/8334a8326dd94d329df351d7da8aefc2/ files/b218cfeb1bc54639af227f922bf6b817.pdf. Accessed 19 Feb 2020 (in Chineses)

13. Group TSC-cte: Experts Consensus on comprehensive treatment of COVID-19 in Shanghai. Zhonghua Chuan Ran Bing Za Zhi. 2020;38(3):134-8. https://doi.org/10.3760/cma.j.issn.1000-6680.2020. 03.002. (in Chinese)

14. Lenzer J. Covid-19: US gives emergency approval to hydroxychloroquine despite lack of evidence. BMJ. 2020;369:m1335. https://doi.org/ 10.1136/bmj.m1335.

15. Indian Council for Medical Research. Recommendation for empiric use of hydroxychloroquine for prophylaxis of SARS-CoV-2 infection. https:// icmr.nic.in/sites/default/files/upload_documents/HCQ_Recommenda tion 22March final MM V2.pdf.

16. Yazdany J, Kim AHJ. Use of hydroxychloroquine and chloroquine during the COVID-19 pandemic: what every clinician should know. Ann Intern Med. 2020. https://doi.org/10.7326/M20-1334.

17. Lim WS, van der Eerden MM, Laing R, et al. Defining community acquired pneumonia severity on presentation to hospital: an international derivation and validation study. Thorax. 2003:58(5):377-82. https://doi.org/10.1136/thorax.58.5.377.

18. Guo X, Qin Y, Zheng K, et al. Improved glomerular filtration rate estimation using new equations combined with standardized cystatin $C$ and creatinine in Chinese adult chronic kidney disease patients. Clin Biochem. 2014;47(13-14):1220-6. https://doi.org/10.1016/j.clinbiochem. 2014.05.060.

19. Ye C, Cai S, Shen G, et al. Clinical features of rheumatic patients infected with COVID-19 in Wuhan, China. Ann Rheum Dis. 2020;79(8):1007-13. https://doi.org/10.1136/annrheumdis-2020-217627.
20. Zumla A, Chan JF, Azhar El, et al. Coronaviruses-drug discovery and therapeutic options. Nat Rev Drug Discov. 2016;15(5):327-47. https:// doi.org/10.1038/nrd.2015.37.

21. Randolph VB, Winkler G, Stollar V. Acidotropic amines inhibit proteolytic processing of flavivirus prM protein. Virology. 1990;174(2):450-8. https://doi.org/10.1016/0042-6822(90)90099-d.

22. Vincent MJ, Bergeron $\mathrm{E}$, Benjannet $\mathrm{S}$, et al. Chloroquine is a potent inhibitor of SARS coronavirus infection and spread. Virol J. 2005;2:69. https://doi.org/10.1186/1743-422X-2-69.

23. Alia E, Grant-Kels JM. Does hydroxychloroquine combat COVID-19? A timeline of evidence. J Am Acad Dermatol. 2020;83(1):e33-4. https:// doi.org/10.1016/j.jaad.2020.04.031.

24. Gautret P, Lagier JC, Parola P, et al. Hydroxychloroquine and azithromycin as a treatment of COVID-19: results of an open-label nonrandomized clinical trial. Int J Antimicrob Agents. 2020;2020:105949. https://doi.org/10.1016/j.ijantimicag.2020.105949.

25. Kim AHJ, Sparks JA, Liew JW, et al. A rush to judgment? Rapid reporting and dissemination of results and its consequences regarding the use of hydroxychloroquine for COVID-19. Ann Intern Med. 2020;172(12):819-21. https://doi.org/10.7326/M20-1223.

26. Chen Z, Hu J, Zhang Z, Jiang S, Han S, Yan D, Zhuang R, Hu B, Zhang Z. Efficacy of hydroxychloroquine in patients with COVID-19: results of a randomized clinical trial. medRxiv. 2020. https://doi.org/10.1101/2020. 03.22.20040758.

27. Tang W, Cao Z, Han M, et al. Hydroxychloroquine in patients with mainly mild to moderate coronavirus disease 2019: open label, randomised controlled trial. BMJ. 2020;369:m1849. https://doi.org/10. 1136/bmj.m1849.

28. Mallat J, Fadi H, Balkis M, Mohamed MA, Mooty M, Malik A, Nusair A, Bonilla F. Hydroxychloroquine is associated with slower viral clearance in clinical COVID-19 patients with mild to moderate disease: a retrospective study. medRxiv. 2020. https://doi.org/10.1101/2020.04.27. 20082180.

29. Chen C, Yi Z, Huang J, Yin P, Cheng Z, Wu J, Chen S, Zhang Y, Chen B, Lu M, Luo Y, Ju L, Zhang J, Wang X. Favipiravir versus arbidol for COVID-19: a randomized clinical trial. medRxiv. 2020. https://doi.org/10.1101/ 2020.03.17.20037432.

30. Schrezenmeier E, Dorner T. Mechanisms of action of hydroxychloroquine and chloroquine: implications for rheumatology. Nat Rev Rheumatol. 2020;16(3):155-66. https://doi.org/10.1038/s41584-020-0372-X.

31. Xiao AT, Tong YX, Zhang S. Profile of RT-PCR for SARS-CoV-2: a preliminary study from 56 COVID-19 patients. Clin Infect Dis. 2020. https://doi. org/10.1093/cid/ciaa460.

32. Lee N, Allen Chan KC, Hui DS, et al. Effects of early corticosteroid treatment on plasma SARS-associated Coronavirus RNA concentrations in adult patients. J Clin Virol. 2004;31 (4):304-9. https://doi.org/10.1016/j. jcv.2004.07.006.

33. Arabi YM, Mandourah Y, Al-Hameed F, et al. Corticosteroid therapy for critically ill patients with middle east respiratory syndrome. Am J Respir Crit Care Med. 2018;197(6):757-67. https://doi.org/10.1164/rccm. 201706-11720C.

34. Chen RC, Tang XP, Tan SY, et al. Treatment of severe acute respiratory syndrome with glucosteroids: the Guangzhou experience. Chest. 2006;129(6):1441-52. https://doi.org/10.1378/chest.129.6.1441.

35. Li H, Yang SG, Gu L, et al. Effect of low-to-moderate-dose corticosteroids on mortality of hospitalized adolescents and adults with influenza A(H1N1)pdm09 viral pneumonia. Influenza Other Respir Viruses. 2017;11(4):345-54. https://doi.org/10.1111/irv.12456.

36. Shang L, Zhao J, Hu Y, et al. On the use of corticosteroids for 2019-nCoV pneumonia. Lancet. 2020;395(10225):683-4. https://doi.org/10.1016/ S0140-6736(20)30361-5.

37. Eljaaly K, Alireza KH, Alshehri S, et al. Hydroxychloroquine safety: a meta-analysis of randomized controlled trials. Travel Med Infect Dis. 2020:36:101812. https://doi.org/10.1016/j.tmaid.2020.101812.

38. Borba MGS, Val FFA, Sampaio VS, et al. Effect of high vs low doses of chloroquine diphosphate as adjunctive therapy for patients 
hospitalized with severe acute respiratory syndrome coronavirus 2 (SARS-CoV-2) infection: a randomized clinical trial. JAMA Netw Open. 2020;3(4):e208857. https://doi.org/10.1001/jamanetworkopen.2020. 8857.

39. Lane JCE, Weaver J, Kostka K, Duarte-Salles T, Abrahao MTF, Alghoul H, Alser O, Alshammari TM, et al. Safety of hydroxychloroquine, alone and in combination with azithromycin, in light of rapid widespread use for COVID-19: a multinational, network cohort and self-controlled case series study. medRxiv. 2020. https://doi.org/10.1101/2020.04.08.20054 551.

\section{Publisher's Note}

Springer Nature remains neutral with regard to jurisdictional claims in published maps and institutional affiliations.
Ready to submit your research? Choose BMC and benefit from:

- fast, convenient online submission

- thorough peer review by experienced researchers in your field

- rapid publication on acceptance

- support for research data, including large and complex data types

- gold Open Access which fosters wider collaboration and increased citations

- maximum visibility for your research: over 100M website views per year

At BMC, research is always in progress.

Learn more biomedcentral.com/submissions 